\title{
Crystalline and Spherulitic Morphology of Polymers Crystallized in Confined Systems
}

\author{
Chengtao Yu, Qing Xie, Yongzhong Bao, Guorong Shan and Pengju Pan * \\ State Key Laboratory of Chemical Engineering, College of Chemical and Biological Engineering, \\ Zhejiang University, 38 Zheda Road, Hangzhou 310027, China; 21428138@zju.edu.cn (C.Y.); \\ 11528042@zju.edu.cn (Q.X.); yongzhongbao@zju.edu.cn (Y.B.); shangr@zju.edu.cn (G.S.) \\ * Correspondence: panpengju@zju.edu.cn; Tel.: +86-571-8795-1334 \\ Academic Editor: Eamor M. Woo \\ Received: 10 April 2017; Accepted: 15 May 2017; Published: 19 May 2017
}

\begin{abstract}
Due to the effects of microphase separation and physical dimensions, confinement widely exists in the multi-component polymer systems (e.g., polymer blends, copolymers) and the polymers having nanoscale dimensions, such as thin films and nanofibers. Semicrystalline polymers usually show different crystallization kinetics, crystalline structure and morphology from the bulk when they are confined in the nanoscale environments; this may dramatically influence the physical performances of the resulting materials. Therefore, investigations on the crystalline and spherulitic morphology of semicrystalline polymers in confined systems are essential from both scientific and technological viewpoints; significant progresses have been achieved in this field in recent years. In this article, we will review the recent research progresses on the crystalline and spherulitic morphology of polymers crystallized in the nanoscale confined environments. According to the types of confined systems, crystalline, spherulitic morphology and morphological evolution of semicrystalline polymers in the ultrathin films, miscible polymer blends and block copolymers will be summarized and reviewed.
\end{abstract}

Keywords: crystalline morphology; confined crystallization; ultrathin film; polymer blend; block copolymer

\section{Introduction}

Crystalline structure and morphology are key factors determining the physical performances of semicrystalline polymers. A variety of physical properties of semicrystalline polymers such as mechanical, thermal and optical properties are drastically influenced by the spherulite size and overall crystallinity, which are also affected by the types of nucleation, crystal growth rate and the characteristics of individual folded chains. Confined crystallizations of polymers under specific environments have recently attracted much attention from the scientific and technological viewpoints. Confinement of polymer systems can be generally classified into three categories according to their confined environments, and they are one, two and three dimensions, respectively. Confined crystallization of polymers has been found in a variety of systems, such as polymer ultrathin films [1-5], polymer blends [6-10], block copolymers [11-14], polymer droplets [15-17], self-assembled polymer nanostructures [18-22], polymers segregated inside nanoporous templates [23-29] and polymer nanocomposites [30-33]. In the past few years, the crystallization of polymers or polymer segments confined in ultrathin films (thickness $<100 \mathrm{~nm}$ ), miscible polymer blends and block copolymers has been widely studied for various systems. The unique crystallization kinetics, crystalline morphology, structure and melting process of polymers confined in such systems have been reviewed in several papers [34-37]. 
Because of the spatial confinement effects, semicrystalline polymers usually show unique and different spherulitic and crystalline morphology from the bulk state when crystallized in the nanoscale confined systems. Observation and illustration of the spherulitic and crystalline morphology have been of fundamental importance in the study of the confined crystallization of semicrystalline polymers. During the crystallization of polymers in confined systems, spherulitic and crystalline morphology can be investigated via polarized optical microscopy (POM), atomic force microscopy (AFM) and transmission electron microscopy (TEM) in the electric diffraction (ED) mode. Among these techniques, POM has been widely used to observe the spherulitic structure in thick or bulk samples; it is generally not suitable to observe the morphology in ultrathin films. The measurement of the spherulite growth rate by POM is simple; yet, its precision and reliability are only for the case with relatively high crystallization temperature $\left(T_{\mathrm{c}}\right)$ where the spherulite growth rate is slow and the nucleation density is low. AFM is a non-destructive technique and is able to obtain the nanoscale structural information of film materials both in situ and in real time under different environments. In situ AFM studies give the opportunity to observe the developing spherulites at a lamellar scale [38]. Real-time AFM has been shown to be very efficient to image the secondary crystallization in crystalline/amorphous polymer blends [39]. In particular, tapping-mode (TM-AFM) coupled with a hot stage is suitable for tracing the crystallization processes of various polymers in a wide range of temperatures [40]. TM-AFM has been widely employed to observe the crystalline morphology and morphologic evaluation of polymers in isothermal crystallization, melting and annealing processes. Some quantitative data, such as lamellar thickness and the lamellar growth rate of semicrystalline polymers, can be obtained by TM-AFM. However, sometimes, it is hard to assure whether the lamellae are edge-on or flat-on (discussed in the next section) only from the morphological investigation. Therefore, TEM in ED mode has been an optional technique to study the lamellar orientation [40]. In summary, researchers have greatly promoted the understanding of the crystalline morphology, structure and crystallization mechanism of polymers in the confined systems by these techniques.

In recent years, considerable progresses have been made on the study of the crystalline and spherulitic morphology of polymers in the nanoscale confined environments. Although several review papers [34-37,40] have been published recently on the confined crystallization of polymers, most of these papers are focused on the fractional, confined crystallization kinetics or crystalline structure. In this review, we mainly focus on the crystalline and spherulitic morphology of polymers crystallized in the confined environments. On the basis of the types of confinement systems, crystalline, spherulitic morphology and morphological evolution of semicrystalline polymers or polymer segments in the ultrathin films, polymer blends and block copolymers are summarized and discussed in this review, which have been the representative and well-studied systems showing confined crystallization behavior.

\section{Crystalline Morphology of Polymers Confined in Ultrathin Films}

Polymer film has been a suitable system to achieve a better understanding of the fundamentals of confined crystallization. Physical properties of polymers in ultrathin films differ considerably from those observed in the bulk. For example, the segmental mobility, transporting process, chain orientation and surface energy at the interface may become more dominant factors in ultrathin films. This phenomenon requires a better understanding for the industrial applications of polymer films. When the thickness of film reduces to the lamellar thickness or to a small multiple of it, the anisotropic surface properties will take effect because the lamellae cannot rotate freely in such a one-dimensional confinement space. Generally, two preferred orientations are encountered mostly in experiments: flat-on and edge-on lamellae to the substrate surface [41]. The preferential orientation relative to the substrate is influenced by polymer-substrate interactions. For most of the systems investigated so far, lamellae are oriented flat-on to the substrate.

Generally, flat-on lamellae are preferred in the ultrathin films, especially the films with a thickness of less than 20-30 nm. The edge-on lamellae appear when the film thickness increases. It has been 
demonstrated that the edge-on lamellae are preferred when the film thickness is in the range of $100-200 \mathrm{~nm}$ or more [42-44]. The transition of lamellar orientation is usually accompanied by the morphological change during the crystallization of polymer ultrathin films. Typical morphologies associated with the edge-on crystals are spherulitic structures, and those with the flat-on crystals are dendrites or seaweeds [40]. According to Brener et al. [45-47], there are four typical spherulitic morphologies for polymers crystallized in one-dimensional spatial confinement [48-51], i.e., compact seaweed (CS), fractal seaweed (FS), compact dendrite (CD) and fractal dendrite (FD), as illustrated in Figure 1a. To better understand each structure, representative images of these four crystalline morphologies were selected from the literature and are shown in Figure 1b-e.
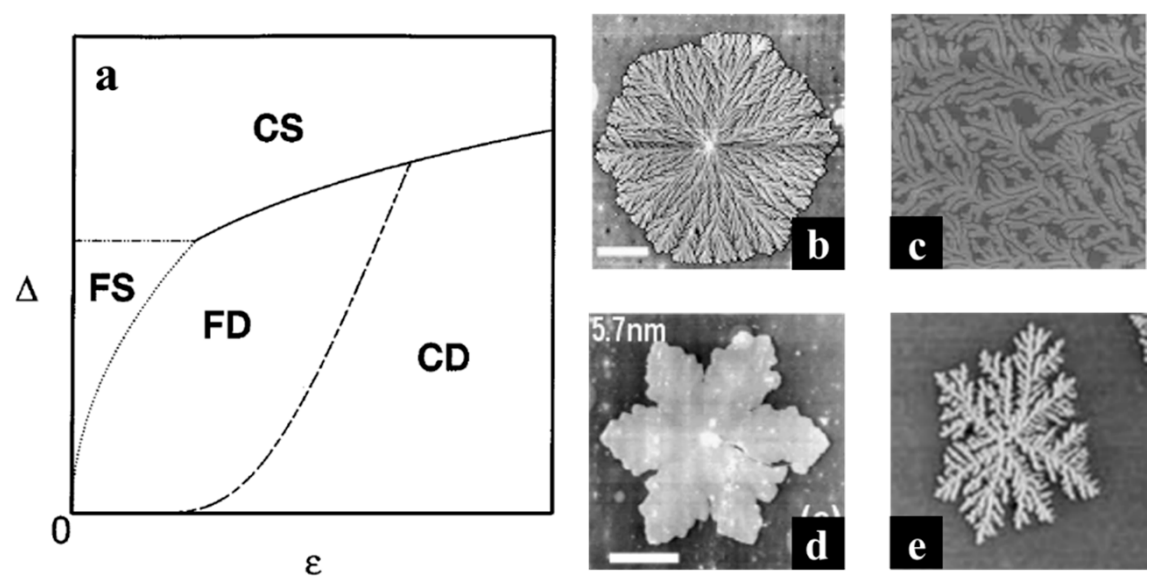

Figure 1. (a) Brener et al.'s morphology diagram for polymer crystallized in one-dimensional spatial confinement. In this diagram, $\Delta$ in the $y$ axis represents the degree of supercooling, and $\varepsilon$ in the $x$ axis represents the crystalline anisotropy; (b-e) Representative crystalline morphologies observed in polymer thin films: (b) Compact seaweed (CS); (c) Fractal seaweed (FS); (d) Compact dendrite (CD); (e) Fractal dendrite (FD) [37]. Copyright 2015. Reproduced with permission from Elsevier Ltd.

The thickness of polymer thin film is a key factor determining its crystalline morphology [37]. On the basis of experimental observations in thin and ultrathin polymer films, the size effects related to film thickness have been widely investigated in the literature [37,48-58]. When the film thickness is much larger than $100 \mathrm{~nm}$, regular spherulites similar to those observed in bulk crystallization are generally formed. Under this condition, crystallization of polymer mainly depends on the surface nucleation process. Nevertheless, the morphological transition frequently takes place when the film thickness is decreased to less than $100 \mathrm{~nm}$. Different crystalline morphologies are generally observed with the reduction of film thickness, as depicted in Figure 1b-e. The formation of such different crystalline patterns in polymer ultrathin films is attributed to the crystal growth in ultrathin films being generally a diffusion-controlled process $[59,60]$.

Mareau and Prud'homme [61] have studied the morphologies of poly(E-caprolactone) (PCL, 1-200 nm) thin films during isothermal crystallization by AFM, as shown in Figure 2. As the film thickness decreased from 200 down to $120 \mathrm{~nm}$, some branched edge-on lamellae, characteristic of the spherulites with radial centrosymmetric organization, were observed (Figure 2a,b). In addition, the size of overgrowths decreased as the film thickness increased. For the PCL film with a thickness of 30-60 nm (Figure 2c,d), most of the overgrowths were shown in flat-on orientation. Specially, when the thickness was $30 \mathrm{~nm}$, the overgrowths did not overlap because of the decreased amount of polymer melt; the radial organization was still present, yet became less obvious (Figure 2d). As the film thickness further decreased to $15 \mathrm{~nm}$, there was only one layer of PCL lamella with a dendritic pattern, characteristic of the diffusion-controlled growth of polymer crystals (Figure 2e). As demonstrated by ED pattern, the flat-on lamellae (without the edge-on lamellae) were exclusively formed under 
these conditions. The width of branches increased with a further decrease of film thickness to $6 \mathrm{~nm}$ (Figure 2f). PCL was not able to crystallize when the film thickness decreased to about $4 \mathrm{~nm}$ [58].
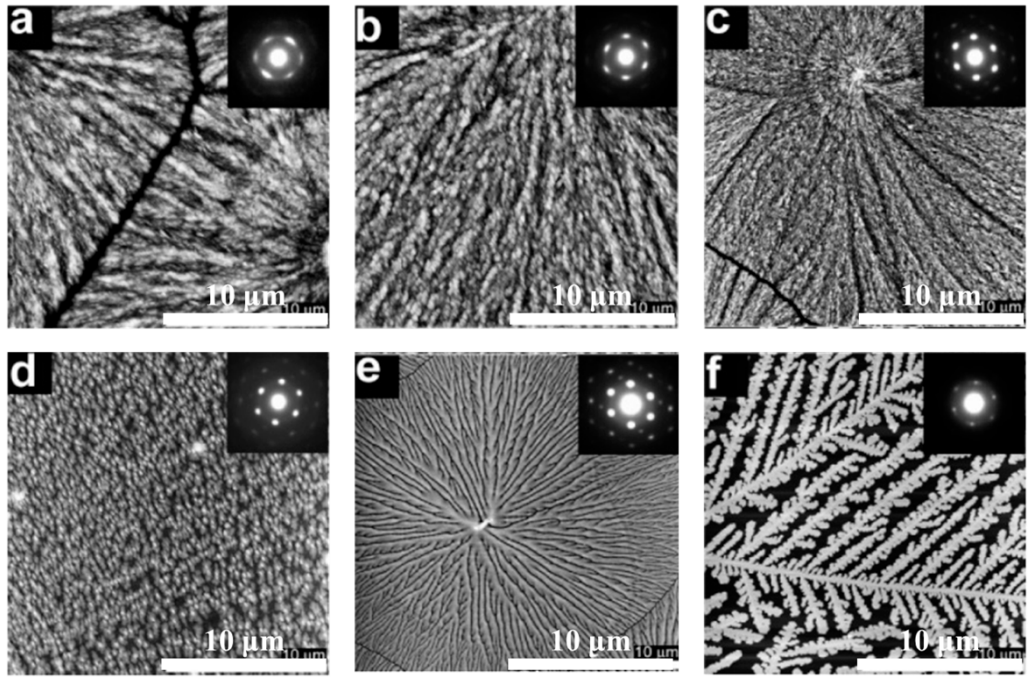

Figure 2. Tapping-mode (TM)-AFM height images $(20 \mu \mathrm{m} \times 20 \mu \mathrm{m})$ of poly( $\varepsilon$-caprolactone) (PCL) thin films crystallized for $24 \mathrm{~h}$ at room temperature at a film thickness of: (a) 200; (b) 120; (c) 60; (d) 30; (e) 15; and (f) $6 \mathrm{~nm}$. Insets show the corresponding electric diffraction (ED) patterns for the selected area [61]. Scale bar: $10 \mu \mathrm{m}$. Copyright 2005. Reproduced with permission from the American Chemical Society.

The substrate and polymer/substrate interactions strongly influence the nucleation and resulting lamellar orientation of polymers in crystallization. Few studies concerning the substrate effects have been carried out $[61,62]$, because the substrate effects are often coupled with the size effects, and these two effects are difficult to split. However, it is believed that the interactions between substrate and polymer should have a profound effect on crystalline morphology. Figure 3 illustrates the different morphologies of PCL thin films crystallized on the carbon-coated substrates. The AFM images showed that the carbon-coated substrates gave slightly different, but comparable morphologies as the Si substrates shown in Figure 2e,f. However, the dendrites grown on carbon-coated substrates had branches with larger widths, which was perhaps due to the polymer/substrate interactions [61].
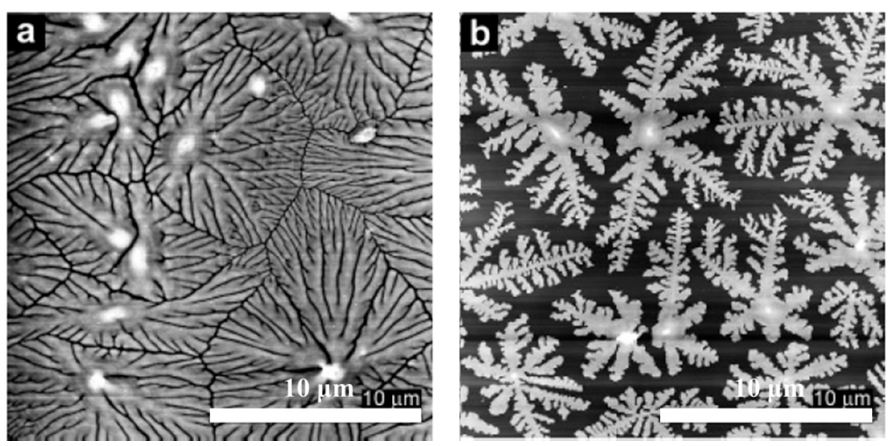

Figure 3. TM-AFM height images of PCL thin films crystallized at room temperature on the carbon-coated substrates at a film thickness of (a) 15 and (b) $6 \mathrm{~nm}$ [61]. Scale bar: $10 \mu \mathrm{m}$. Copyright 2005. Reproduced with permission from the American Chemical Society.

Qiao et al. [58] have examined the effects of $T_{\mathrm{C}}$ and molecular weight on the crystalline morphology of PCL thin film. Because $T_{\mathrm{c}}$ determines the degree of supercooling for polymer in crystallization, it strongly influences the crystalline morphology of polymer thin films, as illustrated in Figure 1a. 
Figure 4 shows the crystalline morphology of PCL thin film crystallized at different $T_{\mathrm{c}}$ 's. The PCL thin film formed a compact seaweed morphology at a lower $T_{\mathrm{c}}$ (i.e., a larger supercooling); while exhibiting fractal-like structure as the $T_{\mathrm{c}}$ increased to $42{ }^{\circ} \mathrm{C}$. This coincided with the phase diagram shown in Figure 1a. The change of crystalline morphologies might be due to the alteration of crystallization kinetics under different degrees of supercooling [46,63]. Figure 5 shows the AFM images of PCL thin film having the same thickness, but different molecular weights. The PCL thin film with high molecular weight showed branches on one side of the stems; yet, that with lower molecular weight exhibited the branches on both sides of the stems. The reason was still unclear and required further study. A plausible explanation for this might be due to the high diffusion ability for the low-molecular-weight PCL.
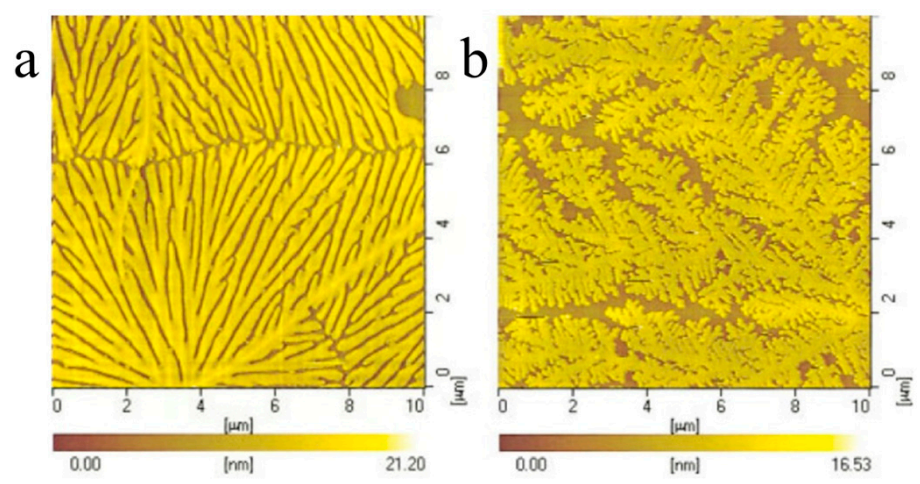

Figure 4. AFM images of PCL thin films crystallized at different temperatures: (a) room temperature, (b) $42{ }^{\circ} \mathrm{C}$ [58]. Image size: $10 \times 10 \mu \mathrm{m}^{2}$. Copyright 2005. Reproduced with permission from John Wiley \& Sons.
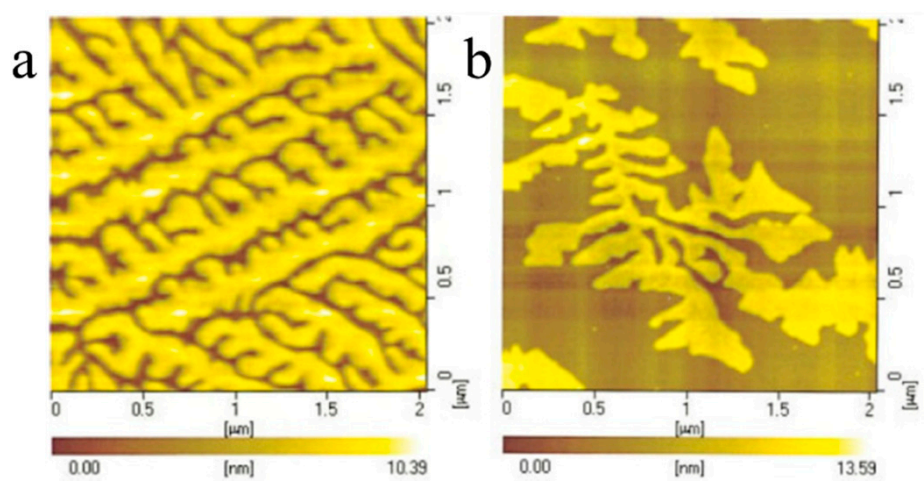

Figure 5. Effect of molecular weight on morphology of PCL thin films crystallized at $42{ }^{\circ} \mathrm{C}$ for $20 \mathrm{~min}$ : (a) $M_{\mathrm{W}}=146,000 ;\left(\right.$ b) $M_{\mathrm{W}}=65,000$ [58]. Image size: $2 \times 2 \mu \mathrm{m}^{2}$. Copyright 2005. Reproduced with permission from John Wiley \& Sons.

The presence of residual solvent also affects the crystalline morphology of PCL thin films. Mareau et al. [51] have investigated the influence of residual tetrahydrofuran (THF) on the crystallization process of PCL ultrathin films by real-time AFM. The morphology of PCL films crystallized at $30^{\circ} \mathrm{C}$ depended strongly on the thermal history, as shown in Figure 6. The films were previously melted at $64{ }^{\circ} \mathrm{C}$, slightly higher than the melting temperature $\left(T_{\mathrm{m}}\right)$ of PCL. A continuous decrease of the width of dendritic branches was observed as the melting period increased (Figure 6), because the increase of melting period decreased the amount of residual solvent in the spin-coated films. It was considered that the residual THF could act as a plasticizer, and the decrease of THF concentration resulted in the lower mobility of PCL chains. 

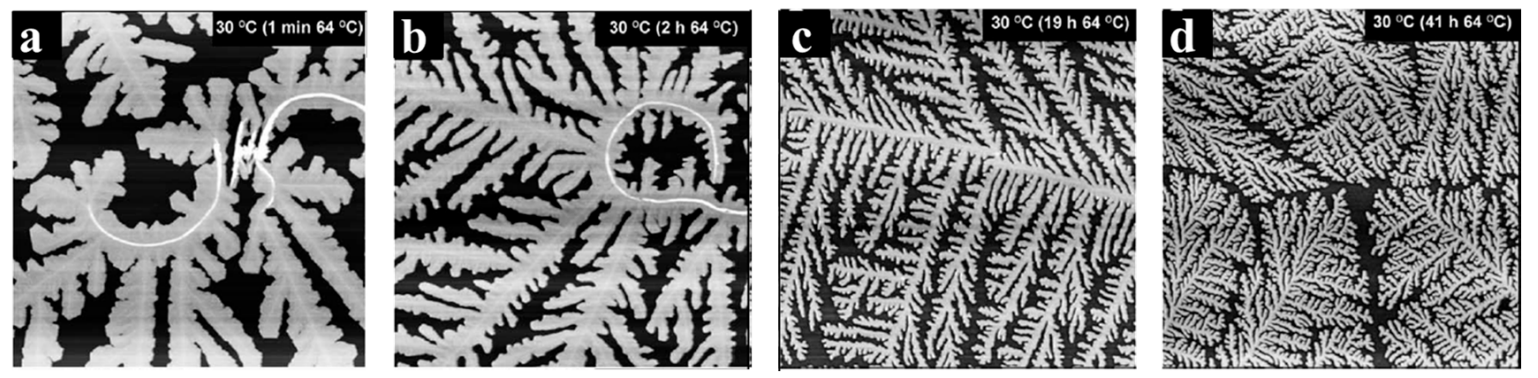

Figure 6. TP-AFM height images $(10 \mu \mathrm{m} \times 10 \mu \mathrm{m})$ of PCL thin film $(6 \mathrm{~nm})$ isothermally crystallized at $30{ }^{\circ} \mathrm{C}$ after thermal treatment at $64{ }^{\circ} \mathrm{C}$ for: (a) $1 \mathrm{~min}$; (b) $2 \mathrm{~h}$; (c) $19 \mathrm{~h}$; and (d) $41 \mathrm{~h}$ [51]. Image size: $10 \times 10 \mu \mathrm{m}^{2}$. Copyright 2005. Reproduced with permission from Elsevier Ltd.

It is notable that the factors such as the sample preparation condition and external force can change the lamellar orientation and crystalline morphology of polymer thin films. Interestingly, the transition of lamellar orientation from edge-on to flat-on could take place when the edge-on lamellae were created by rubbing or scratching amorphous polymer films using AFM tips [43,64-66], but the accurate value of transition thickness was still unknown [40]. The readers can refer to [40,66-68] for more detailed discussion on this aspect.

\section{Crystalline Morphology of Polymers Confined in Miscible Blends}

Polymer blending has been a simple yet efficient method to prepare high-performance materials. Depending on the interactions and miscibility of polymer components, polymer blends can be classified as miscible and immiscible systems. Although the confined crystallization of polymers has been observed in a few immiscible blends [69-74], it is less common because the phase domains of polymer components are usually large and range in the scales of several to several tens of micrometers. However, in the case of miscible polymer blends with one or two crystalline components, the crystallization kinetics and crystalline morphology of crystalline component will be severally influenced by the other component; this is more obvious for the crystalline/crystalline polymer blend systems. Researchers have found that the binary miscible crystalline/crystalline polymers show the confined and fractional crystallization behavior because of the phase separation and segregation in different length scales during crystallization process. These crystalline/crystalline polymer blends included poly(ethylene terephthalate) (PET)/poly(butylene terephthalate) (PBT) [75], poly(3-hydroxybutyrate) (PHB)/poly(ethylene oxide) (PEO) [76,77], poly(vinylidene fluoride) (PVDF)/poly(butylene adipate) (PBA) [78-80], PVDF/poly(butylene succinate-co-butylene adipate) (PBSA) [81], PVDF/PHB [82], PVDF/poly(butylene succinate) (PBS) [83-85], PBS/PEO [86-92], PBS/PBA [93,94], poly(butylene adipate-co-butylene succinate) (PBAS)/PEO [95], poly(ethylene succinate) (PES)/PEO [96], PLLA/poly(oxymethylene) [97,98], and so on. Expect for the miscible blends with one or two crystalline homopolymers, the miscible copolymer/copolymer blends having crystalline components or blocks could also show the confined crystallization behavior $[99,100]$.

Crystalline/crystalline miscible polymer blends are able to exhibit a wide variety of morphologies depending on the temperature. When the blend is cooling from the melt, the polymer component having high $T_{\mathrm{c}}$ and $T_{\mathrm{m}}$ will crystallize first, where the low- $T_{\mathrm{m}}$ component acts as an amorphous phase. Crystallization of the high- $T_{\mathrm{m}}$ component will lead to the phase separation of these two components, and the low- $T_{\mathrm{m}}$ component can reside in the interlamellar, interfibrillar or interspherulitic regions of the crystallized high- $T_{\mathrm{m}}$ component. These interlamellar, interfibrillar or interspherulitic environments will exert diversified confinement effects on the following crystallization of the low- $T_{\mathrm{m}}$ component. The low- $T_{\mathrm{m}}$ component will show the different crystallizabilities when segregated in different environments; this leads to the multistage and fractional crystallizations of the low- $T_{\mathrm{m}}$ polymer component $[78,79,81,84,87,88,90,91,93-95]$. Therefore, the crystalline/crystalline miscible 
polymer blends usually exhibit much more complex morphologic features. We will focus on the crystalline and spherulitic morphology of binary crystalline/crystalline miscible polymer blends in this section.

PBS/PEO blend is a well-studied miscible blend pair showing the confined and fractional crystallization behavior. Effects of blend composition, crystallization conditions of the high- $T_{\mathrm{m}} \mathrm{PBS}$ component and the molecular weights of the low $-T_{\mathrm{m}}$ PEO component on the fractional crystallization kinetics and crystalline morphology of PEO have been symmetrically studied by He et al. and our group $[87,88,90,91]$. Figure 7 shows the DSC cooling curves of PBS/PEO 60/40 blends with different PEO molecular weights after the isothermal crystallization of PBS component at different $T_{\mathrm{c}}{ }^{\prime} \mathrm{s}\left(T_{\mathrm{c}, \mathrm{PBS}}\right.$ 's). The PEO component in PBS/PEO blend with a medium molecular weight $(20 \mathrm{~kg} / \mathrm{mol})$ of PEO exhibited fractional crystallization and crystallized under an extremely large supercooling when the PBS component was crystallized at a high $T_{\mathrm{c}}$ (e.g., $>80{ }^{\circ} \mathrm{C}$ ). However, fractional crystallization of the PEO component in the PBS/PEO blend gradually disappeared as the $T_{\mathrm{c}}$ of the PBS component decreased (Figure $7 b$ ) [90]. As indicated by the results of small-angle X-ray scattering (SAXS), the long period of PBS crystals increased after blending with PEO at a high $T_{\mathrm{c}}$ of the PBS component; yet, it changed little when the $T_{\mathrm{C}}$ of PBS component is low. This indicated that the segregation of PEO in the PBS phase was strongly influenced by the crystallization conditions of PBS. A high $T_{\mathrm{C}}$ of the PBS component facilitated the segregation of PEO within the interlamellar regions of PBS crystals, which exerted a stronger confinement effect on the following crystallization of the PEO component. Furthermore, the fractional crystallization of the PEO component in the PBS/PEO blend was dramatically depressed as the molecular weight of PEG was increased to $100 \mathrm{~kg} / \mathrm{mol}$ or decreased to $2 \mathrm{~kg} / \mathrm{mol}[91]$.

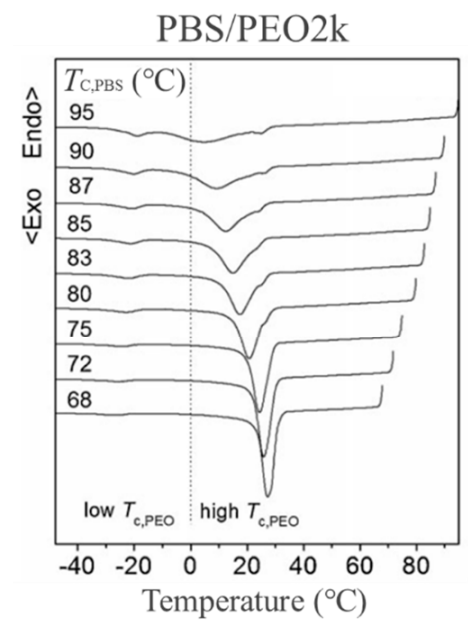

(a)

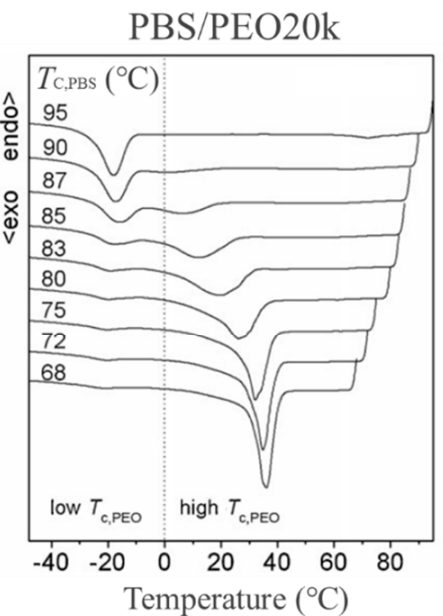

(b)

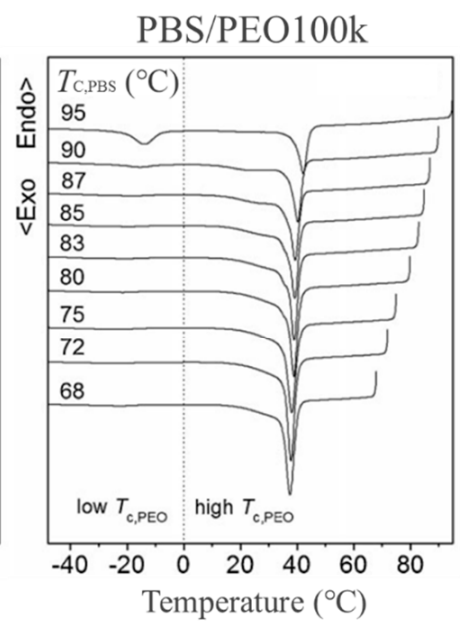

(c)

Figure 7. DSC cooling curves of poly(butylene succinate) (PBS)/poly(ethylene oxide) (PEO) 60/40 blends after the isothermal crystallization of the PBS component at different temperatures. Molecular weights of PEO are 2, 20 and $100 \mathrm{~kg} / \mathrm{mol}$ in $(\mathbf{a}-\mathbf{c})$, respectively. The blends were first melted at $150{ }^{\circ} \mathrm{C}$ for $2 \mathrm{~min}$ and then cooled to $T_{\mathrm{C}, \mathrm{PBS}}$ at $100^{\circ} \mathrm{C} / \mathrm{min}$ and held for sufficient time for the crystallization of the PBS component. The sample was then cooled to $-50{ }^{\circ} \mathrm{C}$ at $10^{\circ} \mathrm{C} / \mathrm{min}$ to detect the crystallization of the PEO component [90,91]. Copyright 2013. Reproduced with permission from John Wiley \& Sons.

Confined crystallization behavior was also reported for the PVDF/PBA $[79,80]$ and PVDF/PBS [84,85] crystalline/crystalline miscible blends. Yang et al. systematically investigated the fractional crystallization kinetics, crystalline morphology and polymorphic structure of PVDF/PBA blends $[79,80]$. In the PVDF/PBA blends, a small amount of PVDF could act as the nucleating agent and accelerate the crystallization of the PBA component; while a large amount of PVDF hindered the crystallization of PBA due to the confinement effects. PBA is a typical polymorphic polymer, 
and it can form different crystal modifications with varying $T_{\mathrm{c}}$ 's. A higher $T_{\mathrm{c}}$ favors the formation of thermodynamically-stable $\alpha$ polymorph; yet, a lower $T_{\mathrm{c}}$ facilitates the growth of the metastable $\beta$ polymorph. Interestingly, the polymorphic structure of PBA could be regulated upon blending with PVDF. The presence of PVDF facilitated PBA to form the thermally more stable $\alpha$ crystals and also accelerated the phase transition from $\beta$ to $\alpha$ crystals of PBA during the annealing process $\left(48^{\circ} \mathrm{C}\right)$ [79]. For the PVDF/PBA blends with a fixed composition, further investigations of Yang et al. also demonstrated that the polymorphic crystalline structure of the PBA component was influenced by the crystallization conditions of PVDF component; this may account for the different segregation areas of the PBA component during the crystallization of PVDF [80]. For a certain PVDF/PBA blend, a higher $T_{\mathrm{C}}$ of PVDF was favorable for the fractional crystallization of PBA component, which tended to segregate in the interlamellar regions of PVDF crystals under these conditions; this was similar to the case of the PBS/PEO blend [90]. Interestingly, a lower $T_{\mathrm{C}}$ (e.g., $80^{\circ} \mathrm{C}$ ) of the PVDF component facilitated the formation of PBA $\alpha$ crystals in both the isothermal and non-isothermal melt crystallizations and also favored the $\beta$-to- $\alpha$ phase transition of PBA during annealing at elevated temperatures. However, PBA showed faster enzymatic degradation in the PVDF/PBA blends with a lower $T_{c}$ of the PVDF component, attributable to the preferential formation of $\alpha$ crystals under these conditions. This study has provided a new method to control the crystal modification and physical properties of polymorphic PBA in their miscible blend systems [80].

In the PVDF/PBS blend, the preexisting PVDF crystal is not a strong nucleator for the following of PBS; thus, the PBS nuclei and crystals can grow relatively slow in the scaffold of PVDF spherulites. Therefore, it is possible to observe the detailed morphological evolution for the confined growth of PBS crystals in the spherulitic matrix of PVDF. Wang et al. [84] have investigated the crystalline morphology of PVDF/PBS blends crystallized at different conditions, as shown in Figure 8. During the crystallization of PVDF at $155^{\circ} \mathrm{C}$, the PBS component was in the molten state, and the PVDF component formed large spherulites (Figure 8a). After the complete crystallization of the PVDF component, the temperature was decreased to $80{ }^{\circ} \mathrm{C}$ for the crystallization of the PBS component. As shown in Figure $8 b-d$, several crystallized PBS domains were found to nucleate and grew continuously in the preexisting PVDF spherulites until the domains impinged on each other. Crystallization of PBS did not change the extinction feature of the preexisting PVDF spherulites, implying that the PBS component crystallized in the lamellar crystals with the same orientation as PVDF.
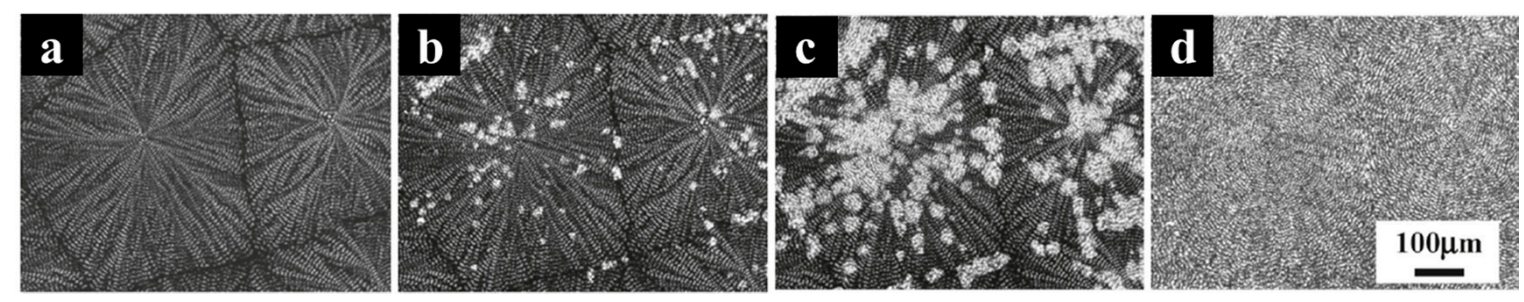

Figure 8. POM micrographs of PVDF/PBS 50/50 blend (a) crystallized first at $155{ }^{\circ} \mathrm{C}$ and then quenched to $80^{\circ} \mathrm{C}$ for (b) 0.5, (c) 1.5 and (d) $20 \mathrm{~min}$ for the crystallization of PBS [84]. Copyright 2011. Reproduced with permission from the American Chemical Society.

PBS/PBA blend is another miscible system showing the confined and fractional crystallization behavior, in which both components have similar chemical structures and are biodegradable [94]. Fractional crystallization of PBA component occurring in the PBS/PBA blends depended strongly on the content and $T_{\mathrm{C}}$ of the PBS component; this was related to the distribution of PBA in the PBS phase. Crystallization of PBA was suppressed in the PBA/PBS blend, due to the physical confinement effects of PBS crystals. According to the morphological observation, Yang et al. have found that the spherulite growth direction of PBA was influenced by that of PBS in the PBS/PBA blends [94]. Figure 9 shows the POM micrographs of PBS/PBA 50/50 blends in the two-step crystallization process. After the 
complete crystallization of PBS at $60{ }^{\circ} \mathrm{C}$, the spherulites of PBS occupied the whole space (Figure 9a). After cooling from 60 down to $40^{\circ} \mathrm{C}$, PBA began to nucleate inside the PBS spherulites (Figure 9b-d), leading to the enhanced brightness due to the birefringence of PBA spherulites. Similar phenomena have also been observed in the PBS/PEO [89] and PBAS/PEO blends [95]. As shown in Figure 9, PBA cannot form its own spherulites in crystallization, and the crystallization of PBA did not change the original shape of preexisting PBS spherulites, indicating that the PBA lamellae probably grew along the PBS ones.
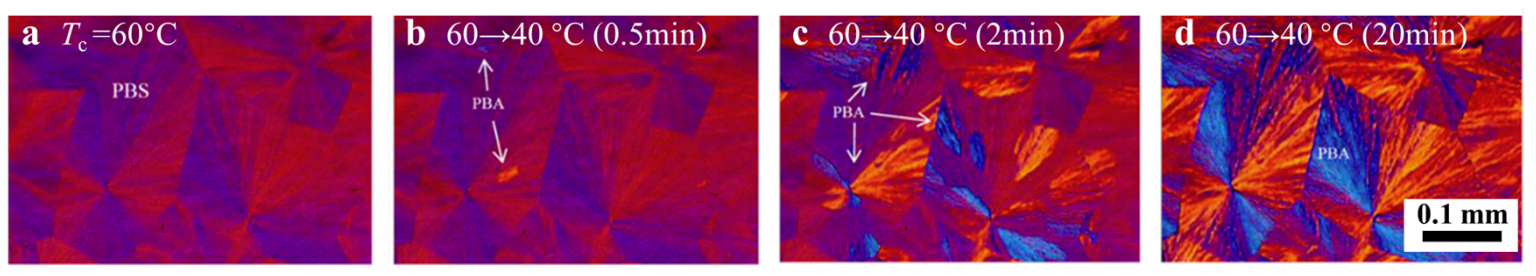

Figure 9. POM micrographs of PBS/PBA 50/50 blends. The blend samples were first cooled from 150 down to $60^{\circ} \mathrm{C}$ for the crystallization of the PBS component (a) and then further cooled to $40{ }^{\circ} \mathrm{C}$ for the crystallization of the PBA component for (b) $0.5 \mathrm{~min}$, (c) $2 \mathrm{~min}$ and (d) $20 \mathrm{~min}$ [94]. Copyright 2011. Reproduced with permission from Elsevier Ltd.

As discussed in the previous section, semicrystalline polymers generally show different crystalline and spherulitic morphologies when crystallized in the ultrathin films. Thus, it is naturally expected that the miscible polymer blends will show a more complicated morphology during crystallization in the ultrathin films. Reports on the crystallization of polymer blends in ultrathin films are few; just the crystallization behavior and morphology of several blend systems such as PEO/poly(methyl methacrylate) (PMMA) [101,102], PCL/poly(vinyl chloride) (PVC) [103], PLLA/PHB [104], PLLA/PBA [105,106] and PLLA/poly(D-lactic acid) (PDLA) blends [107-109] in ultrathin films have been reported in the literature. Among these blend systems, PLLA/PDLA blend is a unique and interesting system because these two isotactic polyenantiomers, PLLA and PDLA, can form stereocomplexes in their blends [110,111]. As mentioned in the previous section, PLLA and PDLA are typical chiral polymers, and their crystalline morphologies are dependent on the chirality during crystallization in the ultrathin films. Therefore, the crystalline morphology of PLLA/PDLA ultrathin film is also sensitive to the chirality.

Prud'homme and coworkers [107] have studied the crystalline morphology of PLLA/PDLA blend in ultrathin film. The overall crystal shape strongly depended on the ratio of two polyenantiomers in the blends, film thickness and $T_{\mathrm{c}}$. Figure 10 shows the optical micrographs of PLLA/PDLA blended ultrathin films (thickness $\sim 20 \mathrm{~nm}$ ) with different blend compositions crystallized at $200^{\circ} \mathrm{C}$. The growth tips in PLLA/PDLA non-equivalent blends were triangular (Figure 10a-d,g); yet those in equivalent blends were hexagonal (Figure 10f). Interestingly, the crystalline curvature direction of PLLA/PDLA blends in ultrathin films was influenced by the chirality of the rich component. For the PLLA-rich PLLA/PDLA blends, the sense of curvature was always anticlockwise (Figure 10b-d). However, the sense of curvature became clockwise for the PDLA-rich blends (Figure 10g). For the PLLA/PDLA blend with $60 \%$ of PLLA, the dendritic crystals having nearly a triangular shape and no curvature were observed after crystallization (Figure 10e). As the PLLA content increased to $75 \%$, the morphology of crystals changed to curved dendrite (Figure 10d). The curved dendrites became less branched, and the radius of curvature increased with the further increase of PLLA content (Figure 10a-c). 

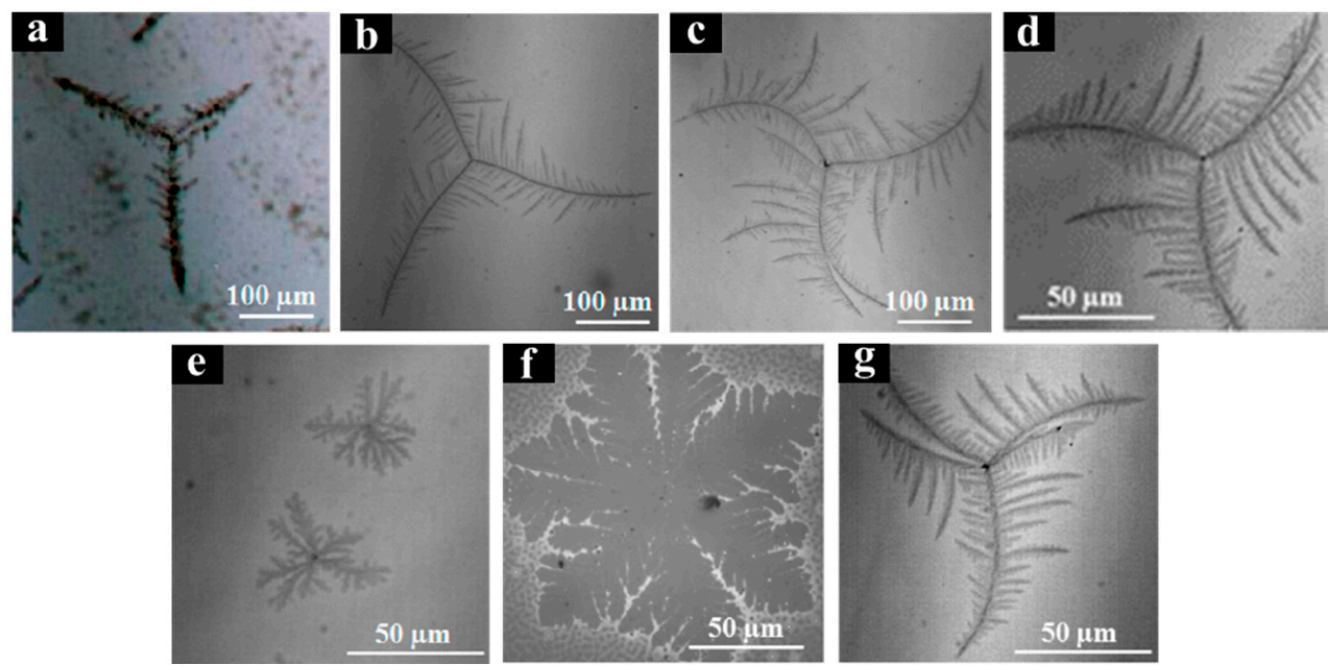

Figure 10. Optical micrographs of PLLA/poly(D-lactic acid) (PDLA) blended films (thickness $20 \mathrm{~nm}$ ) crystallized at $200{ }^{\circ} \mathrm{C}$. The mass fractions of PLLA were: (a) 95\%; (b) 90\%; (c) $85.7 \%$; (d) $75 \%$; (e) $60 \%$; (f) $50 \%$; and (g) $25 \%$ [107]. Copyright 2010. Reproduced with permission from the American Chemical Society.

Prud'homme and coworkers [108] have studied the effects of film thickness on the morphology of PLLA/PDLA blends (PLLA content $=75 \%$ ) during crystallization at $200{ }^{\circ} \mathrm{C}$. The dendritic crystals became more compact as the film thickness increased. Crystalline lamellae bent anticlockwise when the film thickness was between 16 and $30 \mathrm{~nm}$. Interestingly, the triangular dendrites packed more densely and showed no curvature when the film thickness was $40 \mathrm{~nm}$. The blend formed non-dendritic single crystals when the film thickness was increased to $50 \mathrm{~nm}$. In addition, they have also investigated the crystalline morphology of PLLA/PDLA blended ultrathin film (PLLA content $=25 \%$; thickness $=$ $20 \mathrm{~nm}$ ) crystallized at different $T_{\mathrm{c}}$ 's [108]. The morphology of this blend transformed from dendrite to seaweed with decreasing $T_{\mathrm{c}}$. It was proposed that the curvature of stereocomplex lamellae was ascribed to the unequal amount of PLLA and PDLA segments at the crystal growth front, creating an unbalanced mechanical stress at the chain folding surfaces that could be released by the curvature of the growth tip.

\section{Crystalline Morphology of Polymer Segments Confined in Block Copolymers}

Block copolymers can self-assemble into a diversity of ordered structures with nanoscale periodicities via microphase separation. Their structures can be controlled by changing the composition of block copolymer or the segregation strength between different blocks. Crystallization can be confined within the microdomains of copolymer for strongly segregated systems, or it can drive the structure formation for weakly segregated melts or homogeneous systems. This makes the crystallizable block copolymers representative systems having confined crystallization behavior, especially in the strong segregation regime [52]. Confined crystallization has been widely observed in the diblock copolymers having double crystalline blocks, such as PEO-b-PCL [112-116], PLLA-b-PEO [117-122], PLLA-b-PCL [123-125], poly(p-dioxanone) (PPDX)-b-PCL [126-128], polyolefin-based block copolymers [129-135], and so on. The confined crystallization kinetics and crystalline morphology of such block copolymers have been extensively studied.

The crystalline morphology of diblock copolymers having double crystalline blocks depended on the segregation strength between the blocks and their copolymer composition. In addition, the order-disorder transition temperature, $T_{\mathrm{c}}$ and glass-transition temperature $\left(T_{\mathrm{g}}\right)$ of each block also influenced the final crystalline morphology of the block copolymer. In the crystallization of block copolymers having double crystalline blocks, the high- $T_{\mathrm{c}}$ block crystallizes first and forms 
spherulites when cooled from the melt; during which the low- $T_{\mathrm{c}}$ block acts as amorphous chains and segregates into the interlamellar regions of the high- $T_{\mathrm{c}}$ block. Upon the further cooling process, the low- $T_{\mathrm{c}}$ block crystallizes under spatial confinement provided by the crystalline lamellae of high- $T_{\mathrm{c}}$ block [37]. This case is somewhat similar to the factional and confined crystallization occurring in the crystalline/crystalline binary miscible blends discussed in the previous section. However, the confined effect of high- $T_{\mathrm{c}}$ crystalline lamellae on the crystallization of the low- $T_{\mathrm{c}}$ component is usually more significant in the block copolymers because the blocks are covalently linked. Müller and coworkers have done many works on the confined crystallization and morphology of double crystalline block copolymers; research progresses in this area have been summarized in the reviews of Müller and coworkers [37,136].

In this section, we use the biodegradable or biocompatible double crystalline block copolymers such as PCL- $b$-PEO, PLLA- $b$-PEO and PLLA- $b$-PCL as examples to address the crystallization and crystalline morphology of polymer segments confined in block copolymers. PCL, PEO and PLA are all biocompatible polymers; their block copolymers exhibit drug permeability and degradability and have been utilized for a wide range of medical applications. Both the drug permeability and biodegradability of these block copolymers depend on their crystallinity, crystalline structure and morphology, which are directly related to their practical applications.

Jiang et al. [112] have studied the crystallization and morphology of PEO-b-PCL diblock copolymers. In these block copolymers, the two blocks have similar $T_{\mathrm{c}}$ and $T_{\mathrm{m}}$; therefore, they can crystallize simultaneous under the same $T_{\mathrm{c}}$. However, the crystallization rates of two blocks could be tuned by their weight fractions. PEO- $b$-PCL diblock copolymers formed the ring-banded spherulites, which were absent in the crystallization of PEO and PCL homopolymers. He et al. [114] have found that the PEO- $b$-PCL diblock copolymers with a PCL mass fraction of $50 \%$ formed a unique crystal morphology. At the beginning, many PCL spherulites were generated and grew slowly. PEO crystals were then nucleated on the PCL spherulites and grew rapidly to form as the outer portion of the concentric spherulites. They further studied the morphology of PEO- $b$-PCL diblock copolymers with different compositions [115], as shown in Figure 11. When the weight fraction of PCL block was 16-36\% and 56-87\%, only the spherulites of PEO and PCL were observed, respectively. Similarly, the PEO-b-PCL diblock copolymers with a PCL weight fraction of $43 \%$ and $50 \%$ formed the concentric spherulites. They proposed that the effect of PCL crystals on the nucleation of the PEO block might be negligible, because the crystal structures of PCL and PEO were different. PEO crystals might be nucleated on the same nuclei for PCL spherulites, leading to the formation of the unique concentric spherulites.

Different from the above-mentioned PEO- $b$-PCL copolymers, the two blocks of PLLA- $b$-PEO copolymers have much different $T_{\mathrm{c}}$ 's and $T_{\mathrm{m}}$ 's. Therefore, the orders of crystallization could be well tuned in PLLA- $b$-PEO copolymers by altering the crystallization conditions. Sun et al. [117] have studied the crystallization behavior, structural development and morphology evolution in a series of PLLA- $b$-PEO diblock copolymers. PLLA-b-PEO diblock copolymers could form spherulites with banded textures and single crystals with an abundance of screw dislocations. Yang et al. [122] have studied the confined crystallization behavior of PLLA- $b$-PEO copolymers. They crystallized the block copolymers by two steps: the PLLA block crystallized fully at $110^{\circ} \mathrm{C}$ in the first step; then the PEO block crystallized by cooling to $30^{\circ} \mathrm{C}$ in the next step. During the crystallization of the PLLA block, the amorphous PEO chains would segregate in the different regions relative to the crystalline lamellae of PLLA crystals, leading to the confined crystallization of PEO in the further cooling process. POM and AFM results indicated that the PEO block crystallized in the multi-length scales of amorphous regions confined by PLLA crystals. The PEO block could crystallize in both interlamellar and interfibrillar regions of PLLA crystals; the subsequent crystallization of PEO block did not alter the spherulitic morphology of PLLA formed in the first step of crystallization. 


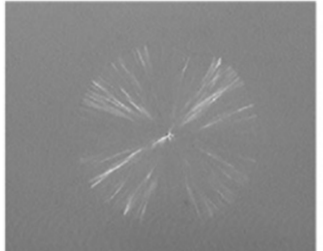

(a) PEO5k, 2s

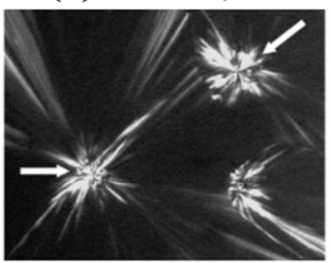

(e) PEOCL43, 104s

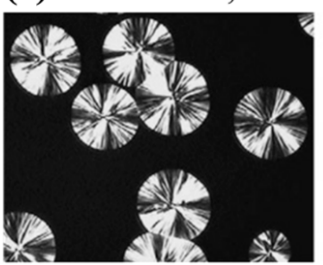

(i) PEOCL68, 93 $\mathrm{s}$

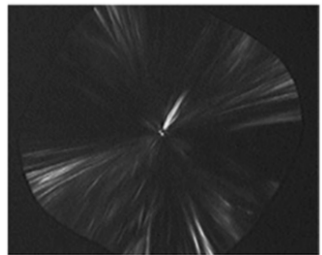

(b) PEOCL16, 6s

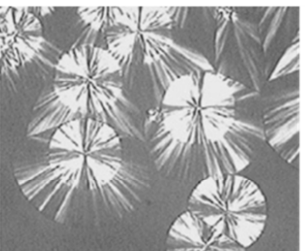

(f) PEOCL50, 90s

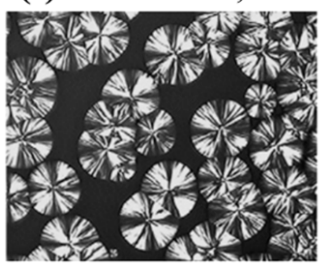

(j) PEOCL77, 97s

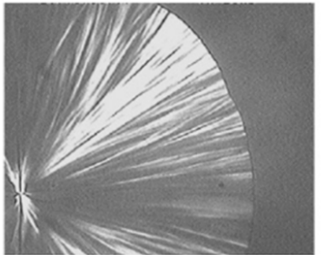

(c) PEOCL29, 14s

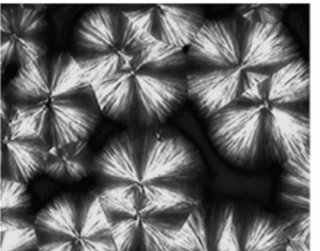

(g) PEOCL56, 180s

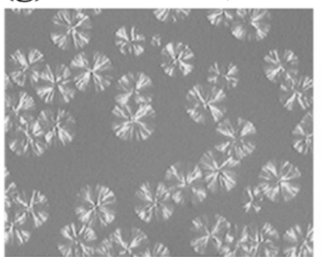

(k) PEOCL87, 90s

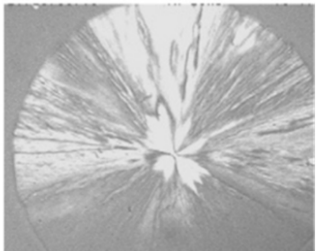

(d) PEOCL36, 13s

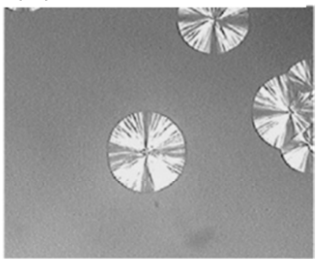

(h) PEOCL62, 90s

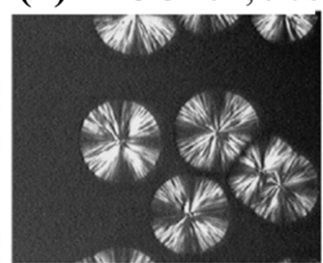

(I) PCL6k, 60s

$100 \mu \mathrm{m}$

Figure 11. POM micrographs for the isothermal crystallization of PEO $\left(M_{n}=5 k\right)$, PCL $\left(M_{n}=6 k\right)$ homopolymers and PEO- $b$-PCL block copolymers with different PCL weight fractions. The samples were melted at $80^{\circ} \mathrm{C}$ for $5 \mathrm{~min}$ and then quenched to $36^{\circ} \mathrm{C}$ for the isothermal crystallization of PCL and PEO blocks. Crystallization time is shown below the graph. Block copolymers were denoted as PEOCL $x$, where $x$ was the weight fraction of the PCL block in copolymer [115]. Copyright 2006. Reproduced with permission from the American Chemical Society.

Castillo et al. [125] have investigated the crystallization and morphology of PLLA- $b$-PCL diblock copolymers. Overall crystallization rates and spherulitic growth rates of the PLLA block decreased with increasing PCL content, because the PCL block acted as a diluent in the crystallization of the PLLA block. PLLA blocks can crystallize in a wide composition range with a spherulitic morphology; PCL blocks crystallized within the previously formed PLLA spherulites. The Maltese cross-extinction patterns tended to become blurry with increasing the PCL fraction. When the weight fraction of the PCL block was $90 \%$, the axialites formed during the isothermal crystallization of the PLLA block. However, after the PCL block was crystallized at $30^{\circ} \mathrm{C}$, the magnitude of birefringence increased drastically in the spherulites; while the morphology and superstructure of previously formed spherulites of PLLA changed little. Although the two blocks were partially miscible in PLLA- $b$-PCL copolymer, the PCL block underwent fractional crystallization for the block copolymers with the PCL fraction between $40 \%$ and $19 \%$. Factional crystallization of the PCL block was induced by the hard confinement of PLLA amorphous and crystalline regions.

In addition, the block copolymers can exhibit a more complicated morphology during crystallization in thin films. Epitaxial crystallization has been used to control the crystallization and morphology of block copolymers in thin films to acquire the oriented crystals and microdomains. De Rosa and coworkers have done many excellent works in this area [137-140]. For example, they have achieved the highly-orientated crystals and microdomains from the polyethylene (PE)-b-poly(ethylene-alt-propylene)- $b$-PE triblock copolymers through epitaxial crystallization, in which the long-range orientation of the crystal unit cell induced the alignment of microdomains [137]. Similarly, they have successfully prepared the epitaxially-crystallized samples of PE-b-syndiotactic 
polypropylene (sPP) copolymers onto the $p$-terphenyl crystals to control the crystallizations of both blocks. The epitaxial crystallization generated oriented overgrowths of $s \mathrm{PP}$ and PE crystals, with an ordered single orientation of sPP lamellae and a double orientation of PE lamellae [139].

\section{Summary}

In this review, we presented the research progress on the crystalline and spherulitic morphology of polymers crystallized in the confined environments. The main emphasis was placed on the introduction of unique crystallization kinetics, crystalline and spherulitic morphology of polymers and polymer segments in ultrathin films, miscible polymer blends and block copolymers. For the polymer ultrathin films, the crystalline morphology was strongly influenced by the film thickness, crystallization condition and molecular weight of the polymers used. In the miscible crystalline/crystalline polymer blends, the low- $T_{\mathrm{m}}$ polymer component usually showed the fractional and confined crystallization due to its distribution into the different regions (interspherulitic, interfibrillar and interlamellar regions) of the high- $T_{\mathrm{m}}$ component. Fractional and confined crystallization of the low- $T_{\mathrm{m}}$ component could be tuned by the blend composition, molecular weight and crystallization conditions of the high- $T_{\mathrm{m}}$ component, which became more significant when the degree of interlamellar segregation was increased. For the block copolymers having double crystalline blocks, the fractional and confined crystallization of the low- $T_{\mathrm{m}}$ block was prevailing, because the low- $T_{\mathrm{m}}$ block tended to segregate into the interlamellar regions of the high- $T_{\mathrm{m}}$ block.

Significant progresses have been achieved in the crystallization kinetics, crystalline and spherulitic morphology of polymers crystallized in the confined systems in the last two decades; this is of fundamental importance for further understanding the unique crystallization behavior of polymers in the nanoscale environments. However, we emphasize that the morphology, crystallization kinetics, crystalline structure and structural changes are still the main aspects in the study of the polymer confined crystallization; these topics are usually not isolated and always connect with each other. Furthermore, the confined crystallization and morphology of polymer thin films, polymer blends and block copolymers in practical processing, as well as the relationships between the crystalline morphology and physical properties for the confined polymer systems are key aspects that require further and in-depth investigations, because this is highly essential for controlling and optimizing the physical performances of the resulting materials. Summarily, with all of these progresses in recent years, we anticipate that the research progress on the crystallization and morphology of confined polymer systems can guide the practical processing of polymer materials with multiple compositions and hierarchical structures.

Acknowledgments: This work was financially supported by the National Key Research and Development Program (2016YFC1100801), Natural Science Foundation of China (21422406), State Key Laboratory of Chemical Engineering (SKLChE-16Z) and the Second Level of Zhejiang Province 151 Talent Project.

Author Contributions: This review was written through the contributions of all authors. All authors have given approval to the final version of the manuscript. Chengtao Yu wrote the draft manuscript according to the advice of Pengju Pan, who conceived of the original ideas, guided the work and finalized the writing. Qing Xie, Yongzhong Bao and Guorong Shan further proofread and gave valuable suggestions.

Conflicts of Interest: The authors declare no conflict of interest.

\section{References}

1. Li, L.; Chan, C.M.; Yeung, K.L.; Li, J.X.; Ng, K.M.; Lei, Y. Direct observation of growth of lamellae and spherulites of a semicrystalline polymer by AFM. Macromolecules 2001, 34, 316-325. [CrossRef]

2. Wang, Y.; Chan, C.M.; Ng, K.M.; Li, L. What controls the lamellar orientation at the surface of polymer films during crystallization. Macromolecules 2008, 41, 2548-2553. [CrossRef]

3. Zhai, X.; Wang, W.; Zhang, G.; He, B. Crystal pattern formation and transitions of PEO monolayers on solid substrates from nonequilibrium to near equilibrium. Macromolecules 2006, 39, 324-329. [CrossRef] 
4. Sakai, Y.; Imai, M.; Kaji, K.; Tsuji, M. Tip-splitting crystal growth observed in crystallization from thin films of poly(ethylene terephthalate). J. Cryst. Growth 1999, 203, 244-254. [CrossRef]

5. Jeon, K.; Krishnamoorti, R. Morphological behavior of thin linear low-density polyethylene films. Macromolecules 2008, 41, 7131-7140. [CrossRef]

6. Santana, O.O.; Müller, A.J. Homogeneous nucleation of the dispersed crystallisable component of immiscible polymer blends. Polym. Bull. 1994, 32, 471-477. [CrossRef]

7. Morales, R.A.; Arnal, M.L.; Müller, A.J. The evaluation of the state of dispersion in immiscible blends where the minor phase exhibits fractionated crystallization. Polym. Bull. 1995, 35, 379-386. [CrossRef]

8. Arnal, M.L.; Müller, A.J. Fractionated crystallisation of polyethylene and ethylene/olefin copolymers dispersed in immiscible polystyrene matrices. Macromol. Chem. Phys. 1999, 200, 2559-2560. [CrossRef]

9. Arnal, M.L.; Müller, A.J.; Maiti, P.; Hikosaka, M. Nucleation and crystallization of isotactic poly(propylene) droplets in an immiscible polystyrene matrix. Macromol. Chem. Phys. 2000, 201, 2493-2504. [CrossRef]

10. Tol, R.; Mathot, V.B.F.; Reynaers, H.; Goderis, B.; Groeninckx, G. Confined crystallization phenomena in immiscible polymer blends with dispersed micro- and nanometer sized PA6 droplets. Part 4: Polymorphous structure and (meta)-stability of PA6 crystals formed in different temperature regions. Polymer 2005, 46, 2966-2977. [CrossRef]

11. Huang, C.; Jiao, L.; Zeng, J.; Zhang, J.; Yang, K.; Wang, Y. Fractional crystallization and homogeneous nucleation of confined PEG microdomains in PBS-PEG multiblock copolymers. J. Phys. Chem. B 2013, 117, 10665-10676. [CrossRef] [PubMed]

12. Zeng, J.; Zhu, Q.; Lu, X.; He, Y.; Wang, Y. From miscible to partially miscible biodegradable double crystalline poly(ethylene succinate)-b-poly(butylene succinate) multiblock copolymers. Polym. Chem. 2012, 3, 399-408. [CrossRef]

13. Fu, J.; Wei, Y.; Xue, L.; Luan, B.; Pan, C.; Li, B.; Han, Y. Lamella reorientation in thin films of a symmetric poly(L-lactic acid)-block-polystyrene upon crystallization at different temperatures. Polymer 2009, 50, 1588-1595. [CrossRef]

14. Ho, R.-M.; Lin, F.-H.; Tsai, C.-C.; Lin, C.-C.; Ko, B.-T.; Hsiao, B.S.; Sics, I. Crystallization-induced undulated morphology in polystyrene-b-poly(L-lactic acid) block copolymer. Macromolecules 2004, 37, 5985-5994. [CrossRef]

15. Sanandaji, N.; Oka, A.; Haviland, D.B.; Tholén, E.A.; Hedenqvist, M.S.; Gedde, U.W. Inkjet printing as a possible route to study confined crystal structure. Eur. Polym. J. 2013, 49, 203-208. [CrossRef]

16. Carvalho, J.L.; Dalnoki-Veress, S.K. Surface nucleation in the crystallisation of polyethylene droplets. Eur. Phys. J. E 2011, 34, 1-6. [CrossRef] [PubMed]

17. Massa, M.V.; Carvalho, J.L.; Dalnoki-Veress, K. Direct visualisation of homogeneous and heterogeneous crystallisation in an ensemble of confined domains of poly(ethylene oxide). Eur. Phys. J. 2003, 12, 111-117. [CrossRef] [PubMed]

18. Yin, L.; Lodge, T.P.; Hillmyer, M.A. A stepwise "micellization-crystallization" route to oblate ellipsoidal cylindrical and bilayer micelles with polyethylene cores in water. Macromolecules 2012, 45, 9460-9467. [CrossRef]

19. Schmelz, J.; Karg, M.; Hellweg, T.; Schmalz, H. General pathway toward crystalline-core micelles with tunable morphology and corona segregation. ACS Nano 2012, 5, 9523-9534. [CrossRef] [PubMed]

20. Yin, L.G.; Hillmyer, M.A. Disklike micelles in water from polyethylene-containing diblock copolymers. Macromolecules 2011, 44, 3021-3028. [CrossRef]

21. Lee, M.K.; Bang, J.; Shin, K.; Lee, J. Fabrication of water-soluble nanocrystals using amphiphilic block copolymer patterned surfaces. Cryst. Growth Des. 2010, 10, 5187-5192. [CrossRef]

22. Osichow, A.; Rabe, C.; Vogtt, K.; Narayanan, T.; Harnau, L.; Drechsler, M.; Ballauff, M.; Mecking, S. Ideal polyethylene nanocrystals. J. Am. Chem. Soc. 2013, 135, 5-50. [CrossRef] [PubMed]

23. Michell, R.M.; Lorenzo, A.T.; Müller, A.J.; Lin, M.C.; Blaszczyk-Lezak, I.; Martín, J.; Mijangos, C. The crystallization of confined polymers and block copolymers infiltrated within alumina nanotube templates. Macromolecules 2012, 45, 1517-1528. [CrossRef]

24. Suzuki, Y.; Duran, H.; Steinhart, M.; Butt, H.J.; Floudas, G. Homogeneous crystallization and local dynamics of poly(ethylene oxide) (PEO) confined to nanoporous alumina. Soft Matter 2013, 9, 2621-2628. [CrossRef] 
25. Lin, M.C.; Nandan, B.; Chen, H.L. Mediating polymer crystal orientation using nanotemplates from block copolymer microdomainsand anodic aluminium oxide nanochannels. Soft Matter 2012, 8, 7306-7322. [CrossRef]

26. Martín-Fabiani, I.; García-Gutiérrez, M.C.; Rueda, D.R.; Linares, A.; Hernández, J.J.; Ezquerra, T.A.; Reynolds, M. Crystallization under one-dimensional confinement in alumina nanopores of poly(trimethylene terephthalate) and its composites with single wall carbon nanotubes. ACS Appl. Mater. Interfaces 2013, 5, 5324-5329. [CrossRef] [PubMed]

27. Michell, R.M.; Blaszczyk-Lezak, I.; Mijangos, C.; Müller, A.J. Confinement induced first order crystallization kinetics for the poly(ethylene oxide) block within a PEO- $b$-PB diblock copolymer infiltrated within alumina nano-porous template. Macromol. Symp. 2014, 337, 109-115. [CrossRef]

28. Suzuki, Y.; Duran, H.; Akram, W.; Steinhart, M.; Floudas, G.; Butt, H.J. Multiple nucleation events and local dynamics of poly(E-caprolactone) (PCL) confined to nanoporous alumina. Soft Matter 2013, 9, 9189-9198. [CrossRef]

29. Guan, Y.; Liu, G.; Ding, G.; Yang, T.; Müller, A.J.; Wan, D. Enhanced crystallization from the glassy state of poly(L-lactic acid) confined in anodic alumina oxide nanopores. Macromolecules 2015, 48, 2526-2533. [CrossRef]

30. Kratochvíl, J.; Rotrekl, J.; Kaprálková, L.; Hromádková, J.; Kelnar, I. Epoxy/poly(E-caprolactone) nanocomposites: Effect of transformations of structure on crystallization. J. Appl. Polym. Sci. 2013, 130, 3197-3204. [CrossRef]

31. Zhen, W.; Lu, C.; Li, C.; Liang, M. Structure and properties of thermo-plastic saponite/poly(vinyl alcohol) nanocomposites. Appl. Clay Sci. 2012, 57, 64-70. [CrossRef]

32. Pan, F.; Jia, H.; Cheng, Q.; Jiang, Z. Bio-inspired fabrication of composite membranes with ultrathin polymer-silica nanohybrid skin layer. J. Membr. Sci. 2010, 362, 119-126. [CrossRef]

33. Yan, S.; Yin, J.; Yang, J.; Chen, X. Structural characteristics and thermal properties of plasticized poly(L-lactide)-silica nanocomposites synthesized by sol-gel method. Mater. Lett. 2007, 61, 2683-2686. [CrossRef]

34. Carr, J.M.; Langhe, D.S.; Ponting, M.T.; Hiltner, A.; Baer, E. Confined crystallization in polymer nanolayered films: A review. J. Mater. Res. 2012, 27, 1326-1350. [CrossRef]

35. Michell, R.M.; Blaszczyk-Lezak, I.; Mijangos, C.; Müller, A.J. Confinement effects on polymer crystallization: From droplets to alumina nanopores. Polymer 2013, 54, 4059-4077. [CrossRef]

36. Zha, L.; Hu, W. Molecular simulations of confined crystallization in the microdomains of diblock copolymer. Prog. Polym. Sci. 2016, 54-55, 232-258. [CrossRef]

37. Michell, R.M.; Müller, A.J. Confined crystallization of polymeric materials. Prog. Polym. Sci. 2016, 54-55, 183-213. [CrossRef]

38. Yuryev, Y.; Wood-Adams, P.; Heuzey, M.-C.; Dubois, C.; Brisson, J. Crystallization of polylactide films: An atomic force microscopy study of the effects of temperature and blending. Polymer 2008, 49, 2306-2320. [CrossRef]

39. Basure, C.; Ivanov, D.A. Evolution of the lamellar structure during crystallization of a semicrystalline amorphous polymer blend: Time-resolved hot-stage SPM study. Phys. Rev. Lett. 2000, 85, 5587-5590. [CrossRef] [PubMed]

40. Liu, Y.; Chen, E. Polymer crystallization of ultrathin films on solid substrates. Coord. Chem. Rev. 2010, 254, 1011-1037. [CrossRef]

41. Wang, Y.; Rafailovich, M.; Sokolov, J.; Gersappe, D.; Araki, T.; Zou, Y.; Kilcoyne, A.D.L.; Ade, H.; Marom, G.; Lustiger, A. Substrate effect on the melting temperature of thin polyethylene films. Phys. Rev. Lett. 2006, 96, 28303. [CrossRef] [PubMed]

42. Ma, Y.; Hu, W.; Reiter, G. Lamellar crystal orientations biased by crystallization kinetics in polymer thin films. Macromolecules 2006, 39, 5159-5164. [CrossRef]

43. Schönherr, H.; Frank, C.W. Ultrathin films of poly(ethylene oxide)s on oxidized silicon. 1. Spectroscopic characterization of film structure and crystallization kinetics. Macromolecules 2003, 36, 1188-1198. [CrossRef]

44. Prud'homme, R.E. Crystallization and morphology of ultrathin films of homopolymers and polymer blends. Prog. Polym. Sci. 2016, 44-45, 214-231. [CrossRef]

45. Brener, E.; Müller-Krumbhaar, H.; Temkin, D. Kinetic phase diagram and scaling relations for stationary diffusional growth. Europhys. Lett. 1992, 17, 535-540. [CrossRef] 
46. Brener, E.; Müller-Krumbhaar, H.; Temkin, D. Structure formation and the morphology diagram of possible structures in two-dimensional diffusional growth. Phys. Rev. E 1996, 54, 2714-2722. [CrossRef]

47. Brener, E.; Müller-Krumbhaar, H.; Temkin, D.; Abel, T. Morphology diagram of possible structures in diffusional growth. Phys. A 1998, 249, 73-81. [CrossRef]

48. Taguchi, K.; Miyaji, H.; Izumi, K.; Hoshino, A.; Miyamoto, Y.; Kokawa, R. Crystal growth of isotactic polystyrene in unltrathin films: Films thickness dependence. J. Macromol. Sci. B 2002, 41, 1033-1042. [CrossRef]

49. Zhu, D.; Shou, X.; Liu, Y.; Chen, E.; Cheng, S.Z. AFM-tip-induced crystallization of poly(ethylene oxide) melt droplets. Acta Polym. Sin. 2006, 4, 553-556. [CrossRef]

50. Taguchi, K.; Toda, A.; Miyamoto, Y. Crystal growth of isotactic polystyrene in ultrathin films: Thickness and temperature dependence. J. Macromol. Sci. B 2006, 45, 1141-1147. [CrossRef]

51. Mareau, V.H.; Prud'homme, R.E. Crystallization of ultrathin poly( $\varepsilon$-caprolactone) films in the presence of residual solvent, an in situ atomic force microscopy study. Polymer 2005, 46, 7255-7265. [CrossRef]

52. Hu, Z.; Huang, H.; Zhang, F.; Du, B.; He, T. Thickness-dependent molecular chain and lamellar crystal orientation in ultrathin poly(di-n-hexylsilane) films. Langmuir 2004, 20, 3271-3277. [CrossRef] [PubMed]

53. Wang, Y.; Ge, S.; Rafailovich, M.; Sokolov, J.; Zou, Y.; Ade, H.; Lüning, J.; Lustiger, A.; Maron, G. Crystallization in the thin and ultrathin films of poly(ethylene-vinyl acetate) and linear low-density polyethylene. Macromolecular 2004, 37, 3319-3327. [CrossRef]

54. Bartczak, Z.; Argon, A.S.; Cohen, R.E.; Kowalewski, T. The morphology and orientation of polyethylene in films of submicron thickness crystallized in contact with calcite and rubber substrates. Polymer 1999, 40, 2367-2380. [CrossRef]

55. Zhou, J.J.; Liu, J.G.; Yan, S.K.; Dong, J.Y.; Li, L.; Chan, C.M.; Schultz, J.M. Atomic force microscopy study of the lamellar growth of isotactic polypropylene. Polymer 2005, 46, 4077-4087. [CrossRef]

56. Jradi, K.; Bistac, S.; Schmitt, M.; Schmatulla, A.; Reiter, G. Enhancing nucleation and controlling crystal orientation by rubbing/scratching the surface of a thin polymer film. Eur. Phys. J. E 2009, 29, 383-389. [CrossRef] [PubMed]

57. Zhong, L.W.; Ren, X.K.; Yang, S.; Chen, E.Q.; Sun, C.X.; Stroeks, A.; Yang, T.Y. Lamellar orientation of polyamide 6 thin film crystallization on solid substrates. Polymer 2014, 55, 4332-4340. [CrossRef]

58. Qiao, C.; Zhao, J.; Jiang, S.; Ji, X.; An, L.; Jiang, B. Crystalline morphology evolution in PCL thin films. J. Polym. Sci. Part B: Polym. Phys. 2005, 43, 1303-1309. [CrossRef]

59. Reiter, G.; Sommer, J. Crystallization of adsorbed polymer monolayers. Phys. Rev. Lett. 1998, 80, 3771-3774. [CrossRef]

60. Wang, M.; Evelyn Meyer, H.B. Branched crystalline patterns formed around poly(ethylene oxide) dots in humidity. Macromol. Rapid Commun. 2002, 23, 853-858. [CrossRef]

61. Mareau, V.H.; Prud'homme, R.E. In-situ hot stage atomic force microscopy study of poly( $\varepsilon$-caprolactone) crystal growth in ultrathin films. Macromolecules 2005, 38, 398-408. [CrossRef]

62. Wang, X.; Zhou, J.; Li, L.; Chan, C. The effect of substrate on the annealing of poly(butylene succinate) single crystals. Macromol. Rapid Commun. 2007, 28, 2001-2006. [CrossRef]

63. Taguchi, K.; Miyaji, H.; Izumi, K.; Hoshino, A.; Miyamoto, Y.; Kokawa, R. Growth shape of isotactic polystyrene crystals in thin films. Polymer 2001, 42, 7443-7447. [CrossRef]

64. Maillard, D.; Prud'homme, R.E. Crystallization of ultrathin films of polylactides: From chain chirality to lamella curvature and twisting. Macromolecules 2008, 41, 1705-1712. [CrossRef]

65. Maillard, D.; Prud'homme, R.E. Chirality information transfer in polylactides: From main-chain chirality to lamella curvature. Macromolecules 2006, 39, 4272-4275. [CrossRef]

66. Fujita, M.; Takikawa, Y.; Sakuma, H.; Teramachi, S.; Kikkawa, Y.; Doi, Y. Real-time observations of oriented crystallization of poly( $\varepsilon$-caprolactone) thin film, induced by an AFM tip. Macromol. Chem. Phys. 2007, 208, 1862-1870. [CrossRef]

67. Kikkawa, Y.; Abe, H.; Iwata, T.; Inoue, Y.; Doi, Y. In situ observation of crystal growth for poly[(S)-lactide] by temperature-controlled atomic force microscopy. Biomacromolecules 2001, 2, 940-945. [CrossRef] [PubMed]

68. Kikkawa, Y.; Abe, H.; Fujita, M.; Iwata, T.; Inoue, Y.; Doi, Y. Crystal growth in poly(L-lactide) thin film revealed by in situ atomic force microscopy. Macromol. Chem. Phys. 2003, 204, 1822-1831. [CrossRef]

69. Tol, R.; Mathot, V.B.F.; Groeninckx, G. Confined crystallization phenomena in immiscible polymer blends with dispersed micro- and nanometer sized PA6 droplets. Part 3: Crystallization kinetics and crystallinity of micro- and nanometer sized PA6 droplets crystallizing at high supercoolings. Polymer 2005, 46, $2955-2965$. [CrossRef] 
70. Tol, R.; Mathot, V.B.F.; Groeninckx, G. Confined crystallization phenomena in immiscible polymer blends with dispersed micro- and nanometer sized PA6 droplets. Part 1: Uncompatibilized PS/PA6 and PPE/PA6 blends. Polymer 2005, 46, 369-382. [CrossRef]

71. Tol, R.; Mathot, V.B.F.; Groeninckx, G. Confined crystallization phenomena in immiscible polymer blends with dispersed micro-and nanometer sized PA6 droplets. Part 2: Reactively compatibilized PS/PA6 and (PPE/PS)/PA6 blends. Polymer 2005, 46, 383-396. [CrossRef]

72. Balsamo, V.; Gouveia, L.M. Interplay of fractionated crystallization and morphology in polypropylene/poly( $\varepsilon$ caprolactone) blends. J. Polym. Sci. Part B Polym. Phys. 2007, 45, 1365-1379. [CrossRef]

73. Zhong, G.; Wang, K.; Zhang, L.; Li, Z.; Fong, H.; Zhu, L. Nanodroplet formation and exclusive homogenously nucleated crystallization in confined electrospun immiscible polymer blend fibers of polystyrene and poly(ethylene oxide). Polymer 2011, 52, 5397-5402. [CrossRef]

74. Yi, H.; Wang, X.; Wei, T.; Lin, H.; Zheng, B. Nanoscale-confined crystallization in epoxy resin and polyethylene-block-poly(ethylene oxide) diblock copolymer blends. Colloid Polym. Sci. 2012, 290, 1347-1352. [CrossRef]

75. Avramova, N. Amorphous poly(ethylene terephthalate)/poly(butylene terephthalate) blends: Miscibility and properties. Polymer 1995, 36, 801-808. [CrossRef]

76. Avella, M.; Martuscelli, E.; Greco, P. Crystallization behaviour of poly(ethylene oxide) from poly(3hydroxybutyrate)/poly(ethylene oxide) blends: Phase structuring, morphology and thermal behavior. Polymer 1991, 32, 1647-1653. [CrossRef]

77. Pan, P.; Zhao, L.; Zhu, B.; He, Y.; Inoue, Y. Fractionated crystallization and self-nucleation behavior of poly(ethylene oxide) in its miscible blends with poly(3-hydroxybutyrate). J. Appl. Polym. Sci. 2010, 117, 3013-3022. [CrossRef]

78. Penning, J.P.; Manley, R.J., St. Miscible blends of two crystalline polymers. 2. Crystallization kinetics and morphology in blends of poly(vinylidene fluoride) and poly(1,4-butylene adipate). Macromolecules 1996, 29, 84-90. [CrossRef]

79. Yang, J.; Pan, P.; Hua, L.; Zhu, B.; Dong, T.; Inoue, Y. Polymorphic crystallization and phase transition of poly(butylene adipate) in its miscible crystalline/crystalline blend with poly(vinylidene fluoride). Macromolecules 2010, 43, 8610-8618. [CrossRef]

80. Yang, J.; Pan, P.; Hua, L.; Feng, X.; Yue, J.; Ge, Y.; Inoue, Y. Effects of crystallization temperature of poly(vinylidene fluoride) on crystal modification and phase transition of poly(butylene adipate) in their blends: A novel approach for polymorphic control. J. Phys. Chem. B 2012, 116, 1265-1272. [CrossRef] [PubMed]

81. Qiu, Z.; Yan, C.; Lu, J.; Yang, W. Miscible crystalline/crystalline polymer blends of poly(vinylidene fluoride) and poly(butylene succinate-co-butylene adipate): Spherulitic morphologies and crystallization kinetics. Macromolecules 2007, 40,5047-5053. [CrossRef]

82. Chiu, H.; Chen, H.; Lin, J. Crystallization induced microstructure of crystalline/crystalline poly(vinylidenefluoride)/poly(3-hydroxybutyrate) blends probed by small angle X-ray scattering. Polymer 2001, 42, 5749-5754. [CrossRef]

83. Li, Y.; Kaito, A.; Horiuchi, S. Biaxially oriented lamellar morphology formed by the confined crystallization of poly(1,4-butylene succinate) in the oriented blend with poly(vinylidene fluoride). Macromolecules 2004, 37, 2119-2127. [CrossRef]

84. Wang, T.; Li, H.; Wang, F.; Yan, S.; Schultz, J.M. Confined growth of poly(butylene succinate) in its miscible blends with poly(vinylidene fluoride): Morphology and growth kinetics. J. Phys. Chem. B 2011, 115, 7814-7822. [CrossRef] [PubMed]

85. Wang, T.; Li, H.; Wang, F.; Schultz, J.M.; Yan, S. Morphologies and deformation behavior of poly(vinylidene fluoride)/poly(butylene succinate) blends with variety of blend ratios and under different preparation conditions. Polym. Chem. 2011, 2, 1688-1698. [CrossRef]

86. Qiu, Z.; Ikehara, T.; Nishi, T. Miscibility and crystallization in crystalline/crystalline blends of poly(butylene succinate)/poly(ethylene oxide). Polymer 2003, 44, 2799-2806. [CrossRef]

87. He, Y.; Zhu, B.; Kai, W.; Inoue, Y. Nanoscale-confined and fractional crystallization of poly(ethylene oxide) in the interlamellar region of poly(butylene succinate). Macromolecules 2004, 37, 3337-3345. [CrossRef]

88. He, Y.; Zhu, B.; Kai, W.; Inoue, Y. Effects of crystallization condition of poly(butylene succinate) component on the crystallization of poly(ethylene oxide) component in their miscible blends. Macromolecules 2004, 37, 8050-8056. [CrossRef] 
89. Ikehara, T.; Kurihara, H.; Kataoka, T. Effect of poly(butylene succinate) crystals on spherulitic growth of poly(ethylene oxide) in binary blends of the two substances. J. Polym. Sci. Part B: Polym. Phys. 2009, 47, 539-547. [CrossRef]

90. Pan, P.; Zhao, L.; Yang, Y.; Inoue, Y. Fractional crystallization and phase segregation in binary miscible poly(butylene succinate)/poly(ethylene oxide) crystalline blends: Effect of crystallization temperature. Macromol. Mater. Eng. 2013, 298, 201-209. [CrossRef]

91. Pan, P.; Zhao, L.; Inoue, Y. Fractional crystallization kinetics of poly(ethylene oxide) in its blends with poly(butylene succinate): Molecular weight effects. Macromol. Mater. Eng. 2013, 298, 919-927. [CrossRef]

92. He, Z.; Liang, Y.; Wang, P.; Han, C.C. Effect of lower critical solution temperature phase separation on crystallization kinetics and morphology of poly(butylene succinate)/poly(ethylene oxide) blend. Polymer 2013, 54, 2355-2363. [CrossRef]

93. Wang, H.; Gan, Z.; Schultz, J.M.; Yan, S. A morphological study of poly(butylene succinate)/poly(butylene adipate) blends with different blend ratios and crystallization processes. Polymer 2008, 49, 2342-2353. [CrossRef]

94. Yang, J.; Pan, P.; Hua, L.; Xie, Y.H.; Dong, T.; Zhu, B.; Inoue, Y.; Feng, X. Fractionated crystallization, polymorphic crystalline structure, and spherulite morphology of poly(butylene adipate) in its miscible blend with poly(butylene succinate). Polymer 2011, 52, 3460-3468. [CrossRef]

95. Ikehara, T.; Kimura, H.; Qiu, Z. Penetrating spherulitic growth in poly(butylene adipate-co-butylene succinate)/poly(ethylene oxide) blends. Macromolecules 2005, 38, 5104-5108. [CrossRef]

96. Wang, H.; Zhao, T.; Wang, X.; Guo, P.; Ren, L.; Qiang, T.; Luo, X.; Qiang, X. Effects of crystallization condition of poly(ethylene succinate) on the crystallization of poly(ethylene oxide) in their blends. Polym. Bull. 2012, 69, 955-965. [CrossRef]

97. Qiu, J.S.; Guan, J.P.; Wang, H.T.; Zhu, S.S.; Cao, X.J.; Ye, Q.L.; Li, Y.J. Enhanced crystallization rate of poly(L-lactic acid) (PLLA) by polyoxymethylene (POM) fragment crystals in the PLLA/POM blends with a small amount of POM. J. Phys. Chem. B 2014, 118, 7167-7176. [CrossRef] [PubMed]

98. Ye, L.J.; Ye, C.C.; Xie, K.Y.; Shi, X.C.; You, J.C.; Li, Y.J. Morphologies and crystallization behaviors in melt-miscible crystalline/crystalline blends with close melting temperatures but different crystallization kinetics. Macromolecules 2015, 48, 8515-8525. [CrossRef]

99. Chu, C.; Chen, H.; Hsiao, M.; Chen, J.; Nandan, B. Crystallization in the binary blends of crystalline-amorphous diblock copolymers bearing chemically different crystalline block. Macromolecules 2010, 43, 3376-3382. [CrossRef]

100. Mayes, A.M.; Russell, T.P.; Deline, V.R.; Satija, S.K.; Majkrzak, C.F. Block copolymer mixtures as revealed by neutron reflectivity. Macromolecules 1994, 27, 7447-7453. [CrossRef]

101. Okerberg, B.C.; Marand, H.; Douglas, J.F. Dendritic crystallization in thin films of PEO/PMMA blends: A comparison to crystallization in small molecule liquids. Polymer 2008, 49, 579-587. [CrossRef]

102. Wang, M.; Braun, H.; Meyer, E. Crystalline structures in ultrathin poly(ethylene oxide)/poly(methyl methacrylate) blend films. Polymer 2003, 44, 5015-5021. [CrossRef]

103. Mamun, A.; Mareau, V.H.; Chen, J.; Prud'homme, R.E. Morphologies of miscible PCL/PVC blends confined in ultrathin films. Polymer 2014, 55, 2179-2187. [CrossRef]

104. Sun, X.; Tokuda, A.; Oji, Y.; Nakatani, T.; Tsuji, H.; Ozaki, Y.; Yan, S.; Takahashi, I. Effects of molar mass of poly(L-lactide acid) on the crystallization of poly[(R)-3-hydroxybutyrate] in their ultrathin blend films. Macromolecules 2012, 45, 2485-2493. [CrossRef]

105. Nurkhamidah, S.; Woo, E.M. Phase-separation-induced single-crystal morphology in poly(L-lactic acid) blended with poly(1,4-butylene adipate) at specific composition. J. Phys. Chem. B 2011, 115, 13127-13138. [CrossRef] [PubMed]

106. Nurkhamidah, S.; Woo, E.M. Phase separation and lamellae assembly below UCST in poly(L-lactic acid)/poly(1,4-butylene adipate) blend induced by crystallization. Macromolecules 2012, 45, 3094-3103. [CrossRef]

107. Maillard, D.; Prud'homme, R.E. Differences between crystals obtained in PLLA-rich or PDLA-rich stereocomplex mixtures. Macromolecules 2010, 43, 4006-4010. [CrossRef]

108. Wang, X.; Prud'homme, R.E. Dendritic crystallization of poly(L-lactide)/poly(D-lactide) stereocomplexes in ultrathin films. Macromolecules 2014, 47, 668-676. [CrossRef] 
109. Marubayashi, H.; Nobuoka, T.; Iwamoto, S.; Takemura, A.; Iwata, T. Atomic force microscopy observation of polylactide stereocomplex edge-on crystals in thin films: Effects of molecular weight on lamellar curvature. ACS Macro Lett. 2013, 2, 355-360. [CrossRef]

110. Tsuji, H. Poly(lactide) stereocomplexes: Formation, structure, properties, degradation, and applications. Macromol. Biosci. 2005, 5, 569-597. [CrossRef] [PubMed]

111. Pan, P.; Han, L.; Bao, J.; Xie, Q.; Shan, G.; Bao, Y. Competitive stereocomplexation, homocrystallization, and polymorphic crystalline transition in poly(L-lactic acid)/poly(D-lactic acid) racemic blends: Molecular weight effects. J. Phys. Chem. B 2015, 119, 6462-6470. [CrossRef] [PubMed]

112. Jiang, S.; He, C.; An, L.; Chen, X.; Jiang, B. Crystallization and ring-banded spherulite morphology of poly(ethylene oxide)-block-poly(E-caprolactone) diblock copolymers. Macromol. Chem. Phys. 2004, 205, 2229-2234. [CrossRef]

113. He, C.; Sun, J.; Deng, C.; Zhao, T.; Deng, M.; Chen, X.; Jing, X. Study of the synthesis, crystallization, and morphology of poly(ethylene glycol)-poly(E-caprolactone) diblock copolymers. Biomacromolecules 2004, 5, 2042-2047. [CrossRef] [PubMed]

114. He, C.; Sun, J.; Zhao, T.; Hong, Z.; Zhuang, X.; Chen, X.; Jing, X. Formation of a unique crystal morphology for the poly(ethylene glycol)-poly( $\varepsilon$-caprolactone) diblock copolymers. Biomacromolecules 2006, 7, 252-258. [CrossRef] [PubMed]

115. He, C.; Sun, J.; Ma, J.; Chen, X.; Jing, X. Composition dependence of the crystallization behavior and morphology of poly(ethylene oxide)-block-poly(e-caprolactone) diblock copolymers. Biomacromolecules 2006, 7, 3482-3489. [CrossRef] [PubMed]

116. Sun, J.; Chen, X.; He, C.; Jing, X. Morphology and structure of single crystals of poly(ethylene glycol)-poly( $\varepsilon$ caprolactone) diblock copolymers. Macromolecules 2006, 39, 3717-3719. [CrossRef]

117. Sun, J.; Hong, Z.; Yang, L.; Tang, Z.; Chen, X.; Jing, X. Study on crystalline morphology of poly(L-lactide)poly(ethylene glycol) diblock copolymer. Polymer 2004, 45, 5969-5977. [CrossRef]

118. Yang, J.; Zhao, T.; Cui, J.; Liu, L.; Zhou, Y.; Li, G.; Zhou, E.; Chen, X. Nonisothermal crystallization behavior of the poly(ethylene glycol) block in poly(L-lactide)-poly(ethylene glycol) diblock copolymers: Effect of the poly(L-lactide) block length. J. Polym. Sci. Part B: Polym. Phys. 2006, 44, 3215-3226. [CrossRef]

119. Yang, J.; Zhao, T.; Liu, L.; Zhou, Y.; Li, G.; Zhou, E. Isothermal crystallization behavior of the poly(L-lactide) block in poly(L-lactide)-poly(ethylene glycol) diblock copolymers: Influence of the PEG block as a diluted solvent. Polym. J. 2006, 12, 1251-1257. [CrossRef]

120. Yang, J.; Zhao, T.; Zhou, Y.; Liu, L.; Li, G.; Zhou, E. Single crystals of the poly(L-lactide) block and the poly(ethylene glycol) block in poly(L-lactide)-poly(ethylene glycol) diblock copolymer. Macromolecules 2007, 40, 2791-2797. [CrossRef]

121. Huang, S.; Jiang, S.; An, L.; Chen, X. Crystallization and morphology of poly(ethylene oxide- $b$-lactide) crystalline-crystalline diblock copolymers. J. Polym. Sci. Part B: Polym. Phys. 2008, 46, 1400-1411. [CrossRef]

122. Yang, J.; Liang, Y.; Luo, J.; Zhao, C.; Han, C.C. Multilength scale studies of the confined crystallization in poly(L-lactide)-block-poly(ethylene glycol) copolymer. Macromolecules 2012, 45, 4254-4261. [CrossRef]

123. Ho, R.-M.; Hsieh, P.-Y.; Tseng, W.-H.; Lin, C.-C.; Huang, B.-H.; Lotz, B. Crystallization-induced orientation for microstructures of poly(L-lactide)-b-poly(e-caprolactone) diblock copolymers. Macromolecules 2003, 36, 9085-9092. [CrossRef]

124. Hamley, I.W.; Parras, P.; Castelletto, V.; Castillo, R.V.; Müller, A.J.; Pollet, E.; Dubois, P.; Martin, C.M. Melt structure and its transformation by sequential crystallization of the two blocks within poly(L-lactide)-blockpoly(e-caprolactone) double crystalline diblock copolymers. Macromol. Chem. Phys. 2006, 207, 941-953. [CrossRef]

125. Castillo, R.V.; Müller, A.J.; Raquez, J.M.; Dubois, P. Crystallization kinetics and morphology of biodegradable double crystalline PLLA-b-PCL diblock copolymers. Macromolecules 2010, 43, 4149-4160. [CrossRef]

126. Müller, A.J.; Albuerne, J.; Marquez, L.; Raquez, J.; Degée, P.; Dubois, P.; Hobbs, J.; Hamley, I.W. Self-nucleation and crystallization kinetics of double crystalline poly( $p$-dioxanone)- $b$-poly( $\varepsilon$-caprolactone) diblock copolymers. Faraday Discuss. 2005, 128, 231-252. [CrossRef] [PubMed]

127. Albuerne, J.; Márquez, L.; Müller, A.J.; Raquez, J.M.; Degée, P.; Dubois, P.; Castelletto, V.; Hameley, I.W. Nucleation and crystallization in double crystalline poly( $p$-dioxanone)-b-poly( $\varepsilon$-caprolactone) diblock copolymers. Macromolecules 2003, 36, 1633-1644. [CrossRef] 
128. Müller, A.J.; Albuerne, J.; Esteves, L.M.; Márquez, L.; Raquez, J.M.; Degée, P.; Dubols, P.; Collins, S.; Hamley, I.W. Confinement effects on the crystallization kinetics and self-nucleation of double crystalline poly(p-dioxanone)- $b$ - poly(E-caprolactone) diblock copolymers. Macromol. Symp. 2004, 215, 369-382. [CrossRef]

129. Ruokolainen, J.; Mezzenga, R.; Fredrickson, G.H.; Kramer, E.H. Morphology and thermodynamic behavior of syndiotactic polypropylene-poly(ethylene-co-propylene) block polymers prepared by living olefin polymerization. Macromolecules 2005, 38, 851-860. [CrossRef]

130. Hamley, I.W.; Fairclough, J.P.A.; Terrill, N.J.; Ryan, A.J. Crystallization in oriented semicrystalline diblock copolymers. Macromolecules 1996, 29, 8835-8843. [CrossRef]

131. Loo, Y.-L.; Register, R.A. Modes of crystallization in block copolymer microdomains: Breakout, templated, and confined. Macromolecules 2002, 35, 2365-2374. [CrossRef]

132. Loo, Y.-L.; Register, R.A. Polymer crystallization confined in one, two, or three dimensions. Macromolecules 2001, 34, 8968-8977. [CrossRef]

133. Rangarajan, P.; Haisch, C.F.; Register, R.A.; Adamson, D.H.; Fetters, L.J. Influence of semicrystalline homopolymer addition on the morphology of semicrystalline diblock copolymers. Macromolecules 1997, 30, 494-502. [CrossRef]

134. Douzinas, K.C.; Cohen, R.E.; Halasa, A.F. Evaluation of domain spacing scaling laws for semicrystalline diblock copolymers. Macromolecules 1991, 24, 4457-4459. [CrossRef]

135. Cohen, R.E.; Cheng, P.-L.; Douzinas, K.; Kofinas, P.; Berney, C.V. Path-dependent morphologies of a diblock copolymer of polystyrene/hydrogenated polybutadiene. Macromolecules 1990, 23, 324-327. [CrossRef]

136. Castillo, R.V.; Müller, A.J. Crystallization and morphology of biodegradable or biostable single and double crystalline block copolymers. Prog. Polym. Sci. 2009, 34, 516-560. [CrossRef]

137. De Rosa, C.; Park, C.; Lotz, B.; Wittmann, J.-C.; Fetters, L.J.; Thomas, E.L. Control of molecular and microdomain orientation in a semicrystalline block copolymer thin film by epitaxy. Macromolecules 2000, 33, 4871-4876. [CrossRef]

138. De Rosa, C.; Park, C.; Thomas, E.L.; Lotz, B. Microdomain patterns from directional eutectic solidification and epitaxy. Nature 2000, 405, 433-437. [CrossRef] [PubMed]

139. De Rosa, C.; Di Girolamo, R.; Auriemma, F.; D'Avino, M.; Talarico, G.; Cioce, C.; Scoti, M.; Coates, G.W.; Lotz, B. Oriented microstructures of crystalline-crystalline block copolymers induced by epitaxy and competitive and confined crystallization. Macromolecules 2016, 49, 5576-5586. [CrossRef]

140. De Rosa, C.; Auriemma, F.; Di Girolamo, R.; Aprea, R.; Thierry, A. Selective gold deposition on a nanostructured block copolymer film crystallized by epitaxy. Nano Res. 2011, 4, 241-248. [CrossRef] 